\title{
Board Certified Family Physician Workforce: Progress in Racial and Ethnic Diversity
}

\author{
Michael R. Peabody, PhD, Aimee R. Eden, PhD, MPH, Montgomery Douglas, MD, \\ and Robert L. Phillips, MD, MSPH
}

Diversification of the physician workforce has been a goal of Association of American Medical Colleges for several years and could improve access to primary care for under-served populations and address health disparities. We found that family physicians' demographics have become more diverse over time, but still do not reflect the national demographic composition. Increased collaboration with undergraduate universities to expand pipeline programs may help increase the diversity of students accepted to medical schools, which in turn should help diversify the family medicine workforce. (J Am Board Fam Med 2018;31:842-843.)

Keywords: Demography, Family Physicians, Medical Schools, Primary Health Care, Students

Racial and ethnic minority physicians are important for the delivery of primary care to underserved populations. ${ }^{1}$ Physicians from underrepresented minority populations are more likely than white physicians to practice primary care in impoverished areas and in regions experiencing physician shortages $^{2}$; however, a significant gap exists between the racial and ethnic composition of the general population and primary care physicians, family medicine faculty, and family medicine residents. ${ }^{2-4} \mathrm{Di}-$ versification of the physician workforce has been a goal of Association of American Medical Colleges for several years ${ }^{4}$ and could improve access to primary care for underserved populations and address health disparities. ${ }^{5}$ Our objectives were to assess how well the racial and ethnic composition of American Board of Family Medicine (ABFM) diplomates (a proxy for the family medicine work-

This article was externally peer reviewed.

Submitted 26 April 2018; revised 21 June 2018; accepted 25 June 2018.

From American Board of Family Medicine, Lexington, KY (MRP, ARE, MD, RLP); Department of Family Medicine, University of Connecticut School of Medicine, Farmington, CT (MD).

Funding: none.

Conflict of interest: $\mathrm{MP}, \mathrm{AE}$, and RP are employees of the American Board of Family Medicine.

Corresponding author: Michael R. Peabody, PhD, 1648 McGrathiana Pkwy, Ste 550, Lexington, KY 40511 (E-mail: mpeabody@theabfm.org). force) mirrors the national population and to determine trends by year of initial certification.

We aggregated racial and ethnic demographic data provided by family physicians during their application for the ABFM Family Medicine Certification Examination from 2013 to 2017 and calculated the percentage of each category by year of initial certification. Examinees were asked to select one race category from the following options: American Indian or Alaska Native, Asian, black or African American, Native Hawaiian or other Pacific Islander, or white. A response option of Other was added in 2017 but was omitted from this analysis. They were also asked to select one ethnicity between either non-Hispanic or Hispanic or Latino. We then compared the racial/ethnic composition of this sample to estimates of the US population by using July 1 , 2017, data from the US Census Bureau. ${ }^{6}$

Data aggregation resulted in matching 66,542 board certified family physicians by their year of initial certification, which ranged from 1987 to 2017. Compared with the US population, ABFM diplomates are more likely to be Asian $(21.8 \%$ vs $5.7 \%)$ or Native Hawaiian or other Pacific Islander ( $0.5 \%$ vs $0.2 \%)$ and less likely to be Black or African American (7.8\% vs $13.3 \%)$, American Indian or Alaska Native (1.0\% vs $1.3 \%)$, or Hispanic or Latino $(9.1 \%$ vs $17.8 \%)$. Non-Hispanic white diplomates are generally representative of the US population (61.2\% vs $61.3 \%)$. The group trends for the 
Figure 1. Proportion of board certified family physicians by group and year of initial certification since 1987.

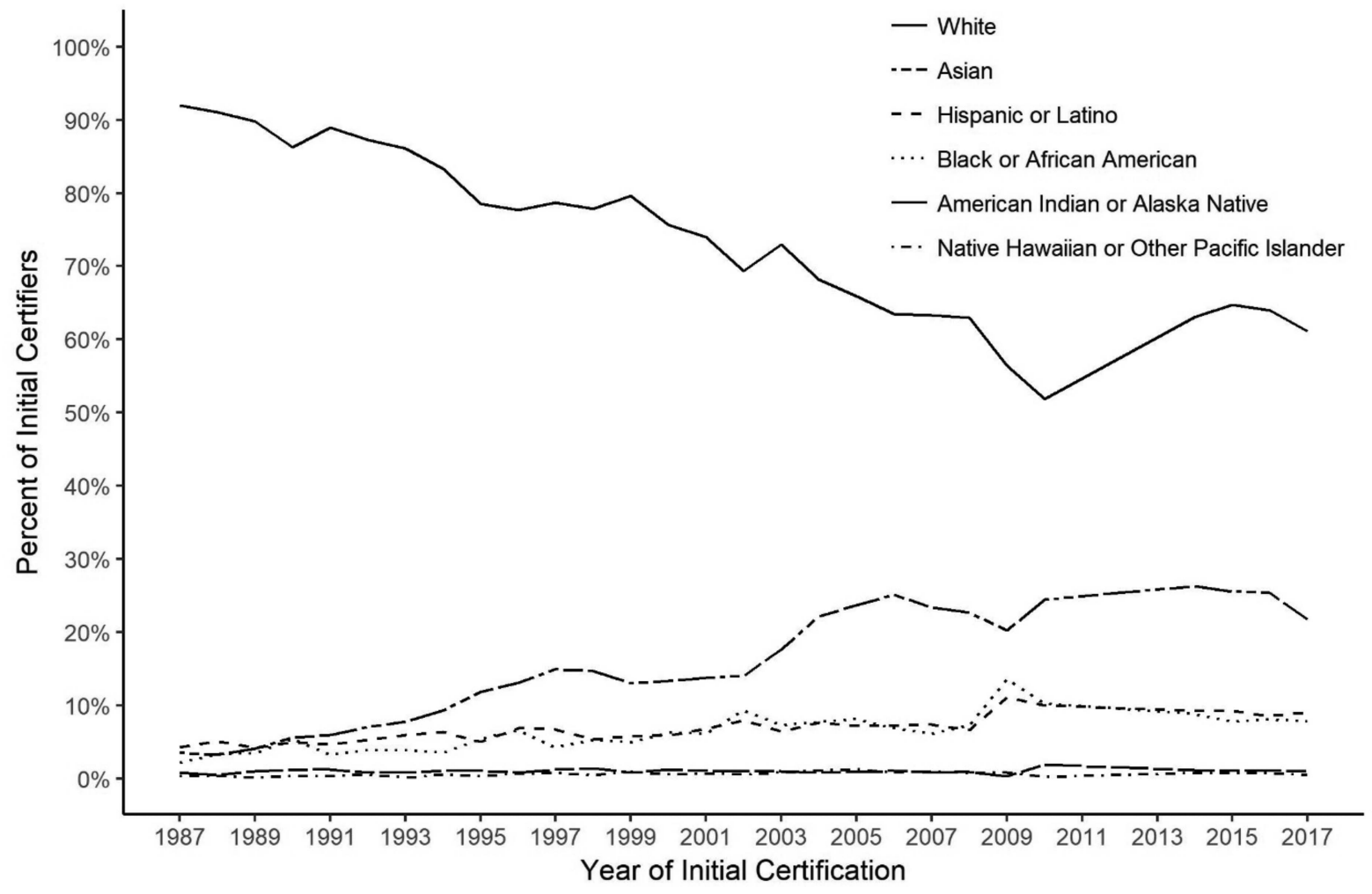

past 30 years (1987 to 2017) in Figure 1 show the percentage of Black or African American physicians increasing from $1.3 \%$ to $7.8 \%$ and Hispanic or Latino physicians increasing from $2.3 \%$ to $9.1 \%$. However, both groups remain substantially underrepresented compared with the general population.

Our results indicate that efforts to increase diversity seem to have been effective for some groups but not all. Black or African Americans and Hispanics, in particular, have struggled to reach a mark representative of the US population. Although family medicine may have the most proportionate distribution of physicians to the general population, ${ }^{2}$ the specialty still feels the effects of a lack of diversity at the undergraduate medical education level. Medical schools should work more closely with their associated universities to increase the number of underrepresented minorities applying to medical school and ensure that these students are appropriately prepared for the rigors of medical school. Increasing the number of pipeline programs (e.g., Health Careers Opportunities Program) may help to recruit a more diverse medical school applicant pool, which in turn should help diversify the family medicine workforce.
To see this article online, please go to: http://jabfm.org/content/ 31/6/842.full.

\section{References}

1. Grumbach K, Mendosa R. Disparity in human resources: Addressing the lack of diversity in the health professions. Health Aff 2008;27:413-22.

2. Xierali IM, Nivet MA. The racial and ethnic composition and distribution of primary care physicians. J Health Care for the Poor and Underserved 2018; 29:556-70.

3. Xierali IM, Nivet MA, Gaglioti AH, Liaw WR, Bazemore AW. Increasing family medicine faculty diversity still lags population trends. J Am Board Fam Med 2017;30:100-3.

4. Nivet MA, Berlin AC. Diversity by design. J Grad Med Ed 2013;5:526-7.

5. Marrast LM, Zallman L, Woolhandler S, Bor DH, McCormick D. Minority physicians' role in the care of underserved patients: diversifying the physician workforce may be key in addressing health disparities. JAMA Intern Med 2014;174:289-91.

6. U.S. Census Bureau. QuickFacts. Available from: https://www.census.gov/quickfacts/fact/table/US/ RHI125216\#viewtop. Accessed April 24, 2018. 